УДК 622.279, 620.193

\title{
НОВЫЙ МЕТОДИЧЕСКИЙ ПОДХОД К ПРОГНОЗИРОВАНИЮ ПОДВЕРЖЕННОСТИ ОБОРУДОВАНИЯ ВЫСОКОТЕМПЕРАТУРНЫХ ГАЗОКОНДЕНСАТНЫХ СКВАЖИН УГЛЕКИСЛОТНОЙ КОРРОЗИИ
}

\author{
Пономарев Александр Иосифович1, \\ pnmrv@mail.ru
}

\author{
Иванов Николай Валерьевич2, \\ inv1412@yandex.ru
}

\author{
Юсупов Александр Дамирович1', \\ aleksandr_yusupov@list.ru \\ 1 Уфимский государственный нефртяной технический университет, \\ Россия, 450062, г. Уфра, ул. Космонавтов, 1. \\ 2 Российский государственный университет нефти и газа (НИУ) им. И.М. Губкина, \\ Россия, 119991, г. Москва, Ленинский пр., 65.
}

\begin{abstract}
Актуальность. Перспективы увеличения добычи газового конденсата - ценного сырья для нефттепереработки и нефртехимии - в значительной мере связаны с дальнейшим освоением ресурсов газоконденсатных залежей в ачимовских отложениях севера Западной Сибири. Большие глубины, аномально высокое пластовое давление и высокая температура низкопродуктивных пластов наряду с присутствием в составе пластового газоконденсатного фрлюида диоксида углерода выдвигают, в первую очередь, повышенные требования к качеству заканчивания скважин и операций гидроразрыва пласта, надежности конструкций и материалов подземного оборудования скважин. Этими фракторами обусловлены высокая стоимость реализации проектов и эксплуатационные риски добычи газа и конденсата, в связи с чем обоснование безопасных условий эксплуатации скважин в ачимовских отложениях является актуальной научно-технической задачей.

Цель: определить предельнье значения термобарических параметров технологических режимов эксплуатации ачимовских газоконденсатных скважин с содержанием в добываемой продукции диоксида углерода, обеспечивающих физико-химические условия отсутствия электрохимической коррозии забойного оборудования - хвостовиков на длительньй (20-летний) период. Объект: пластовый газоконденсатный фрлюид и забойное оборудование трех ачимовских газоконденсатных скважин с хвостовиками из углеродистой стали, нестойкой к углекислотной коррозии.

Метод: моделирование фразового поведения добываемого пластового флюида в скважинных условиях в среде программного обеспечения ГазКондНефрть.

Результаты. Термодинамическими расчетами фразового поведения пластовой газоконденсатной смеси с учетом ее влагосодержания показано, что снижение пластового давления в зоне расположения трех рассматриваемых скважин при разработке участка ачимовской залежи на протяжении 20 лет при проектных технологических режимах их эксплуатации со временем приводит к образованию двухсразной смеси «газ - нестабильный конденсат» в забойных термобарических условиях скважин. При этом водная жидкая фраза вследствие высокой температуры потока на забое скважин не образуется в течение всего расчетного периода. Гидродинамические расчеты параметров восходящего потока газожидкостной смеси показали, что высокие скорости потока скважинной продукции обеспечивают условия полного и непрерывного выноса нестабильного конденсата потоком газа с забоя на поверхность по каждой из рассматриваемых скважин в течение всего 20-летнего периода, тем самым предотвращаются физико-химические условия образования на поверхности хвостовиков электролита и протекания углекислотной коррозии.
\end{abstract}

\section{Ключевые слова:}

Газоконденсатная смесь, диоксид углерода, хвостовик скважины, параметры технологического режима эксплуатации скважины, симулятор, фразовые диаграммы, линии точек росы воды и углеводородов, режим течения многофразного потока, уелекислотная коррозия, антикоррозионный режим эксплуатации скважины.

\section{Введение}

Вопросы углекислотной коррозии как подземного, так и наземного оборудования и промысловых трубопроводов были актуальны в 60-е гг. прошлого столетия при разработке газоконденсатных месторождений Краснодарского и Ставропольского краев [1]. Тогда отмечалась неравномерность коррозии насосно-компрессорных труб (НКТ) на некоторых скважинах. Чаще всего фиксировалась коррозия большей интенсивности в приустьевой зоне, чем в забойной, а на некоторых скважинах коррозия башмака и нижних НКТ не отмечалась вовсе. Наблюдаемые коррозионные поражения НКТ рядом исследователей $[2,3]$ объяснялись тем, что в стволе сква- жин при снижении температуры и давления имеет место выделение из добываемого газа свободной водной жидкой фазы, присутствие которой инициирует процесс коррозии. При этом известно, что конденсационные воды сами по себе обладают небольшой коррозионной агрессивностью по отношению к металлу, но разрушительное действие этих вод многократно увеличивается при насыщении их углекислым газом. Ввиду отсутствия в тот период времени адекватных средств моделирования фазового поведения газоконденсатных смесей с учетом их влагосодержания, а также гидродинамических методов расчета многофазных вертикальных и горизонтальных потоков, исследования по определению гра- 
ничных термодинамических условий существования антикоррозионного режима эксплуатации скважинного и поверхностного оборудования не проводились.

Ачимовские отложения в настоящее время являются основным ресурсом прироста запасов и добычи углеводородного сырья (УВС) и, в первую очередь, газового конденсата в Западной Сибири [4]. Один из крупнейших - Уренгойский лицензионный участок - в свою очередь поделен на шесть эксплуатационных участков [5, 6].

Подземная конструкция большинства скважин на одном из эксплуатационных участков Уренгойского лицензионного участка (эксплуатационная колонна, хвостовик, насосно-компрессорные трубы с комплексом подземного оборудования) имеет коррозионностойкое исполнение. Такое проектное техническое решение обусловлено потенциальной коррозионной агрессивностью пластового флюида из-за содержания в его составе диоксида углерода. Также известно, что на Уренгойском лицензионном участке существует проблема углекислотной коррозии наземного оборудования. Так, элементы устьевой обвязки скважин и отдельные участки газосборных трубопроводов, выполненных в некоррозионно-стойком исполнении, за десятилетний период эксплуатации подверглись воздействию углекислотной коррозии [7-9].

Вместе с тем определение предельных значений термодинамических параметров технологических режимов эксплуатации ачимовских газоконденсатных скважин, обеспечивающих физико-химические условия отсутствия электрохимической коррозии забойного оборудования - хвостовиков, представляет большой практический интерес. При существовании таких режимов в течение длительного периода эксплуатации (несколько десятилетий) можно рассматривать вопрос о внесении изменений в проектную конструкцию новых скважин с применением хвостовиков в некоррозионно-стойком исполнении, что позволит частично снизить стоимость скважин.

\section{Методика проведения исследования}

Типовая конструкция скважин одного из эксплуатационных участков Уренгойского лицензионного участка [10] приведена на рис. 1 и включает:

- кондуктор ( $\mathrm{D}=324$ мм), перекрывающий многолетнемерзлые породы и неустойчивые четвертичные отложения;

- техническую (промежуточную) колонну ( $D=245$ мм), перекрывающую сеноманский горизонт с аномально низкими пластовыми давлениями;

- эксплуатационную колонну ( $\mathrm{D}=178$ мм), перекрывающую пласты с нормальными и аномально низкими пластовыми давлениями с установкой башмака колонны на 20 м выше продуктивного пласта ачимовских отложений;

- хвостовик ( $\mathrm{D}=114$ мм), расположенный в интервале продуктивных пластов;

- лифтовую колонну ( $\mathrm{D}=89$ мм), на которой установлен комплекс подземного оборудования (пакер клапан-отсекатель, датчики давления и температуры и др.).

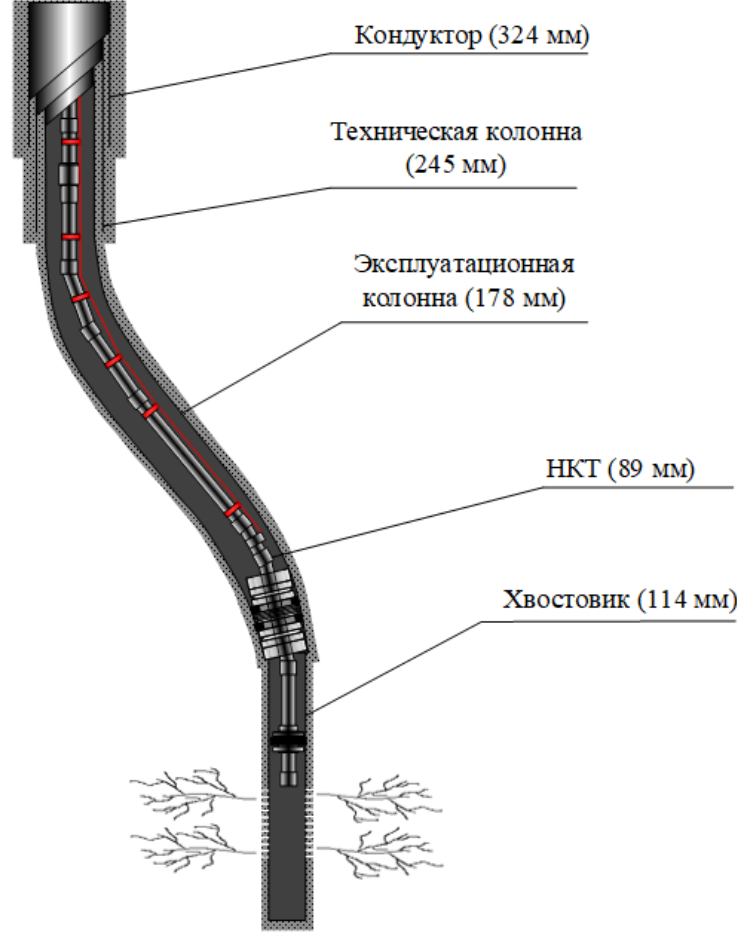

Puc. 1. Типовая конструкция ачимовских скважин Fig. 1. Typical well design for the achimov deposits

В 2020 г. в рамках программы исследовательских работ в эксплуатацию были введены три скважины, конструкция которых предусматривает хвостовики, выполненные в нестойком к коррозии исполнении из углеродистой стали группы прочности Р110. При поверхностном анализе потенциальных рисков, связанных с процессами коррозии хвостовиков, напрашивался вывод о протекании более интенсивной углекислотной коррозии металла хвостовиков в сравнении с коррозией металла поверхностного оборудования ввиду более высоких температур и парциальных давлений углекислого газа, наблюдаемых на забое.

Однако электрохимия углекислотной коррозии такова, что для протекания процесса коррозии металла необходимым условием является наличие на поверхности металла водной жидкой фазы. Считается, что пленка воды на поверхности металла толщиной 20-30 молекул является достаточной для протекания электрохимической коррозии [11], к которой относится углекислотная коррозия, наблюдаемая на наземных объектах добычи УВС ачимовских отложений. Поэтому присутствие воды на забое скважины только в паровой фазе исключает коррозию хвостовиков, несмотря на более высокие температуры и парциальное давление углекислого газа по сравнению с условиями устья скважины, где наблюдаются интенсивные коррозионные процессы.

Для достижения поставленной цели определены следующие задачи исследования:

- для трех опытных скважин определить фазовое состояние воды на забое и устье при составах скважинной продукции, изменяющихся в течение разработки участка залежи по мере снижения пластового и забойного давлений на 20-летний период; 
- предложить рекомендации по противокоррозионной защите и коррозионному мониторингу скважин, оборудованных хвостовиками из углеродистой стали.

Математическое моделирование фазового равновесия для систем природных углеводородов заключается в использовании различных уравнений состояния многокомпонентных систем, описывающих соотношения между параметрами углеводородной смеси в состоянии парожидкостного равновесия [12]. Уравнение состояния Ван-дер-Ваальса послужило основой для всех существующих уравнений и их модификаций, таких как: Редлиха-Квонга [13], Ли-Кеслера [14], Пенга-Робинсона $[15,16]$ и других. Выбор определенного уравнения для расчета фазового равновесия обусловлен диапазонами давления и температуры, а также составом природных газоконденсатных смесей, в который входят углеводороды различного строения (парафиновые, нафтеновые, ароматические) и неуглеводородные вещества (сероводород, диоксид углерода, азот и др.). Все современные программные комплексы, предназначенные для моделирования технологии добычи и подготовки углеводородного сырья, включают уравнение состояния Пенга-Робинсона в той или иной модификации. Адекватность уравнения состояния Пенга-Робинсона применительно к расчету процессов добычи и подготовки углеводородного сырья подтверждается работой [17]. Кроме того, в работаx [18-22] дается рекомендация к использованию уравнения состояния Пенга-Робинсона для моделирования фазового поведения многокомпонентных углеводородных смесей, в т. ч. при пластовых условиях. По этой причине все выполненные технологические расчеты проводились с использованием уравнения состояния Пенга-Робинсона.

В качестве инструментария исследования требовалось определить программный комплекс технологического моделирования, адекватно описывающий фазовое поведение добываемой из ачимовских скважин углеводородной смеси с учетом ее влагосодержания. Проведя анализ применения различных комплексов, описанных в работе [23], для расчетов была выбрана компьютерная программа ГазКондНефть.

В технологической модели «забой - устье скважины» производились расчеты фазового состояния пластового флюида, для чего использовались следующие исходные данные по исследуемым скважинам на 20-летний прогнозный период:

- компонентно-фракционные составы добываемой углеводородной смеси по состоянию на 2020 г.;

- проектные значения технологических режимов эксплуатации скважин: депрессии на пласт, дебиты газоконденсатной смеси и воды.

Методика исследования заключается в последовательном решении следующих задач:

- определение термобарических условий выделения жидкой углеводородной фазы при изменении состава добываемого пластового флюида и параметров технологических режимов скважин в процессе истощения залежи;

- определение фазового состояния воды и возможности ее существования в забойных и устьевых условиях в водной жидкой фазе;

- определение гидродинамических условий полного и непрерывного выноса жидкости с забоя скважины на поверхность.

По результатам решения этих задач проводится анализ фазового состояния добываемого флюида на забое и устье каждой из скважин с точки зрения возможности формирования пленки или слоя водного раствора электролита на внутренней поверхности хвостовика и устьевой обвязки.

Полный состав газоконденсатной смеси для расчета фазового состояния добываемого пластового флюида и проектные параметры технологического режима скважины № 1 на 2020 г. приведены соответственно в табл. 1, 2.

Таблица 1. Компонентно-фракционный состав углеводородной смеси по скважине № 1 на 2020 2.

Table 1. Component-fractional composition of the hydrocarbon fluid for well no. 1 in 2020

\begin{tabular}{|c|c|c|c|c|c|}
\hline $\begin{array}{l}\text { Компоненты и фракции } \\
\text { Components and fractions }\end{array}$ & $\begin{array}{c}\text { Содержание, \% мас. } \\
\text { Content, wt. \% }\end{array}$ & $\begin{array}{l}\text { Фракции } \\
\text { Fractions }\end{array}$ & $\begin{array}{c}\text { Содержание, \% мас. } \\
\text { Content, wt. \% }\end{array}$ & $\begin{array}{l}\text { Фракции } \\
\text { Fractions }\end{array}$ & $\begin{array}{c}\text { Содержание, \% мас. } \\
\text { Content, wt. \% }\end{array}$ \\
\hline Азот/Nitrogen & 0,1590 & $\mathrm{~F}_{9}\left(130-140^{\circ} \mathrm{C}\right)$ & 1,7182 & $\mathrm{~F}_{26}\left(300-310^{\circ} \mathrm{C}\right)$ & $2,39 \cdot 10^{-3}$ \\
\hline $\begin{array}{l}\text { Диоксид углерода } \\
\text { Carbon dioxide }\end{array}$ & 1,3544 & $\mathrm{~F}_{10}\left(140-150^{\circ} \mathrm{C}\right)$ & 0,6482 & $\mathrm{~F}_{27}\left(310-320^{\circ} \mathrm{C}\right)$ & $1,57 \cdot 10^{-3}$ \\
\hline Метан/Methane & 42,4308 & $\mathrm{~F}_{11}\left(150-160^{\circ} \mathrm{C}\right)$ & 1,0133 & $\mathrm{~F}_{28}\left(320-330^{\circ} \mathrm{C}\right)$ & $1,03 \cdot 10^{-3}$ \\
\hline Этан/Ethane & 8,9696 & $\mathrm{~F}_{12}\left(160-170^{\circ} \mathrm{C}\right)$ & 0,3451 & $\mathrm{~F}_{29}\left(330-340^{\circ} \mathrm{C}\right)$ & $6,01 \cdot 10^{-4}$ \\
\hline Пропан/Propane & 8,6921 & $\mathrm{~F}_{13}\left(170-180^{\circ} \mathrm{C}\right)$ & 0,3794 & $\mathrm{~F}_{30}\left(340-350^{\circ} \mathrm{C}\right)$ & $3,22 \cdot 10^{-4}$ \\
\hline Изобутан/Isobutane & 3,3817 & $\mathrm{~F}_{14}\left(180-190^{\circ} \mathrm{C}\right)$ & 0,2779 & $\mathrm{~F}_{31}\left(350-360^{\circ} \mathrm{C}\right)$ & $1,63 \cdot 10^{-4}$ \\
\hline Норм. бутан/n-butane & 5,1723 & $\mathrm{~F}_{15}\left(190-200^{\circ} \mathrm{C}\right)$ & 0,1469 & $\mathrm{~F}_{32}\left(360-370^{\circ} \mathrm{C}\right)$ & $8,68 \cdot 10^{-5}$ \\
\hline Изопентан/i-pentane & 2,6813 & $\mathrm{~F}_{16}\left(200-210^{\circ} \mathrm{C}\right)$ & 0,1100 & $\mathrm{~F}_{33}\left(370-380^{\circ} \mathrm{C}\right)$ & $3,81 \cdot 10^{-5}$ \\
\hline Норм. пентан/n-pentane & 3,1376 & $\mathrm{~F}_{17}\left(210-220^{\circ} \mathrm{C}\right)$ & 0,0899 & $\mathrm{~F}_{34}\left(380-390^{\circ} \mathrm{C}\right)$ & $1,91 \cdot 10^{-5}$ \\
\hline $\mathrm{F}_{1}\left(45-60^{\circ} \mathrm{C}\right)$ & 1,6847 & $\mathrm{~F}_{18}\left(220-230^{\circ} \mathrm{C}\right)$ & 0,0443 & $\mathrm{~F}_{35}\left(390-400{ }^{\circ} \mathrm{C}\right)$ & $9,62 \cdot 10^{-6}$ \\
\hline $\mathrm{F}_{2}\left(60-70^{\circ} \mathrm{C}\right)$ & 2,7769 & $\mathrm{~F}_{19}\left(230-240^{\circ} \mathrm{C}\right)$ & 0,0334 & $\mathrm{~F}_{36}\left(400-410^{\circ} \mathrm{C}\right)$ & $5,15 \cdot 10^{-6}$ \\
\hline $\mathrm{F}_{3}\left(70-80^{\circ} \mathrm{C}\right)$ & 1,3186 & $\mathrm{~F}_{20}\left(240-250^{\circ} \mathrm{C}\right)$ & 0,0277 & $\mathrm{~F}_{37}\left(410-420^{\circ} \mathrm{C}\right)$ & $2,62 \cdot 10^{-6}$ \\
\hline $\mathrm{F}_{4}\left(80-90^{\circ} \mathrm{C}\right)$ & 2,2671 & $\mathrm{~F}_{21}\left(250-260^{\circ} \mathrm{C}\right)$ & 0,0173 & $\mathrm{~F}_{38}\left(420-430^{\circ} \mathrm{C}\right)$ & $1,46 \cdot 10^{-6}$ \\
\hline $\mathrm{F}_{5}\left(90-100^{\circ} \mathrm{C}\right)$ & 3,0199 & $\mathrm{~F}_{22}\left(260-270^{\circ} \mathrm{C}\right)$ & 0,0132 & $\mathrm{~F}_{39}\left(430-440^{\circ} \mathrm{C}\right)$ & $6,52 \cdot 10^{-7}$ \\
\hline $\mathrm{F}_{6}\left(100-110^{\circ} \mathrm{C}\right)$ & 4,2434 & $\mathrm{~F}_{23}\left(270-280^{\circ} \mathrm{C}\right)$ & 0,0095 & $\mathrm{~F}_{40}\left(440-450^{\circ} \mathrm{C}\right)$ & $2,28 \cdot 10^{-7}$ \\
\hline $\mathrm{F}_{7}\left(110-120^{\circ} \mathrm{C}\right)$ & 2,6816 & $\mathrm{~F}_{24}\left(280-290^{\circ} \mathrm{C}\right)$ & 0,0063 & $\mathrm{~F}_{41}\left(450-460^{\circ} \mathrm{C}\right)$ & $1,14 \cdot 10^{-7}$ \\
\hline $\mathrm{F}_{8}\left(120-130^{\circ} \mathrm{C}\right)$ & 1,1382 & $\mathrm{~F}_{25}\left(290-300^{\circ} \mathrm{C}\right)$ & 0,0041 & $\mathrm{~F}_{42}\left(460-470^{\circ} \mathrm{C}\right)$ & $4,65 \cdot 10^{-8}$ \\
\hline
\end{tabular}


Таблица 2. Параметры проектного технологического режима скважины № 1 в 2020 г.

Table 2. Parameters of the design technological regime of well no. 1 in 2020

\begin{tabular}{|c|c|}
\hline $\begin{array}{l}\text { Параметр } \\
\text { Parameter }\end{array}$ & $\begin{array}{c}\text { Значение } \\
\text { Value }\end{array}$ \\
\hline $\begin{array}{l}\text { Расход углеводородной смеси, тыс. } \mathrm{m}^{3} / \mathrm{u} \\
\text { (тыс. } \mathrm{m}^{3} / \text { сутки) } \\
\text { Hydrocarbon fluid consumption, thousand } \mathrm{m}^{3} / \text { hour } \\
\text { (thousand } \mathrm{m}^{3} / \text { day) }\end{array}$ & $\begin{array}{c}9,59 \\
(230,16)\end{array}$ \\
\hline $\begin{array}{l}\text { Расход пластовой воды, }{ }^{3} / \text { сут } \\
\text { Formation water consumption, } \mathrm{m}^{3} / \text { day }\end{array}$ & 1,05 \\
\hline $\begin{array}{l}\text { Забойное давление, МПа } \\
\text { Bottomhole pressure, MPa }\end{array}$ & 38,72 \\
\hline $\begin{array}{l}\text { Температура на забое } \\
\text { Bottomhole temperature, }{ }^{\circ} \mathrm{C}\end{array}$ & 108,00 \\
\hline $\begin{array}{l}\text { Устьевое давление, МПа } \\
\text { Wellhead pressure, MPa }\end{array}$ & 28,35 \\
\hline $\begin{array}{l}\text { Температура на устье } \\
\text { Wellhead temperature, }{ }^{\circ} \mathrm{C}\end{array}$ & 45,76 \\
\hline
\end{tabular}

\section{Результаты расчетов}

Данные табл. 1, 2 были экспортированы в симулятор для решения двух первых задач моделирования фазовых превращений добываемого из скважины № 1 флюида. Изменение компонентно-фракционного состава добываемой газоконденсатной смеси с укрупненными фракциями по скважинам № 1-3 по годам разработки приведено в табл. 3.

По результатам расчетов также определены области двухфазного состояния воды и углеводородов в газоконденсатной смеси, ограниченные соответствующими линиями точек росы (нулевыми изоплерами), для изменяющихся в процессе разработки компонентно-фракционных составов добываемого пластового флюида. При этом следует отметить, что в расчетах на симуляторе использовались полные составы углеводородной смеси, аналогичные приведенным в табл. 1. Смещение границ двухфазной области для воды и углеводородов по состоянию на 2020, 2030 и 2040 гг. по скважинам № 1-3 представлены на диаграммах рис. 2-4, соответственно. На диаграммах также указаны термобарические условия на забое и устье в соответствии с проектными технологическими режимами эксплуатации скважин на вышеупомянутые годы разработки участка ачимовской залежи.

Таблица 3. Изменение компонентно-фракиионного состава добываемой газоконденсатной смеси с укрупненными фракииями по скважинам № 1-3 (2020, 2030, 2040 гг.)

Table 3. Change in the component-fractional composition of the produced gas-condensate mixture with enlarged fractions for wells no. 1-3 (in 2020, 2030, 2040)

\begin{tabular}{|c|c|c|c|c|c|c|c|c|c|}
\hline \multirow{3}{*}{$\begin{array}{l}\text { Компонент } \\
\text { Component }\end{array}$} & \multicolumn{9}{|c|}{$\begin{array}{c}\text { Содержание компонента/фракции, \% масс. (кроме воды) } \\
\text { Component/fraction content, wt. \% (except water) }\end{array}$} \\
\hline & \multicolumn{3}{|c|}{$\begin{array}{c}\text { Скважина № } 1 \\
\text { Well no. } 1 \\
\end{array}$} & \multicolumn{3}{|c|}{$\begin{array}{l}\text { Скважина № } 2 \\
\text { Well no. } 2 \\
\end{array}$} & \multicolumn{3}{|c|}{$\begin{array}{c}\text { Скважина № } 3 \\
\text { Well no. } 3\end{array}$} \\
\hline & 2020 & 2030 & 2040 & 2020 & 2030 & 2040 & 2020 & 2030 & 2040 \\
\hline Метан/Methane & 42,43 & 51,29 & 54,87 & 47,13 & 54,77 & 58,13 & 45,90 & 52,18 & 57,93 \\
\hline Этан/Ethane & 8,97 & 10,28 & 10,67 & 8,57 & 9,75 & 10,32 & 8,38 & 9,35 & 10,28 \\
\hline Пропан/Propane & 8,69 & 9,11 & 9,03 & 6,80 & 7,55 & 7,90 & 6,67 & 7,31 & 7,87 \\
\hline Изобутан/Isobutane & 3,38 & 3,26 & 3,10 & 2,27 & 2,48 & 2,56 & 2,23 & 2,42 & 2,55 \\
\hline Норм. Бутан/n-butane & 5,17 & 4,73 & 4,39 & 3,18 & 3,42 & 3,49 & 3,13 & 3,35 & 3,49 \\
\hline Изопентан/i-pentane & 2,68 & 2,18 & 1,92 & 1,42 & 1,48 & 1,48 & 1,40 & 1,47 & 1,48 \\
\hline Норм. пентан/n-pentane & 3,14 & 2,46 & 2,13 & 1,59 & 1,65 & 1,63 & 1,57 & 1,65 & 1,63 \\
\hline $\begin{array}{l}\Phi_{1}\left(\text { фракция } 45-100^{\circ} \mathrm{C}\right) \\
\mathrm{F}_{1}\left(\text { fraction } 45-100^{\circ} \mathrm{C}\right)\end{array}$ & 11,07 & 7,21 & 5,86 & 5,62 & 5,27 & 4,74 & 5,61 & 5,49 & 4,78 \\
\hline $\begin{array}{l}\Phi_{2}\left(\text { фракция } 100-200^{\circ} \mathrm{C}\right) \\
\left.\mathrm{F}_{2} \text { (fraction } 100-200^{\circ} \mathrm{C}\right)\end{array}$ & 12,59 & 7,45 & 5,93 & 12,25 & 9,41 & 6,94 & 12,41 & 10,79 & 7,11 \\
\hline $\begin{array}{l}\Phi_{3}\left(\text { фракция } 200-300^{\circ} \mathrm{C}\right) \\
\mathrm{F}_{3}\left(\text { fraction } 200-300^{\circ} \mathrm{C}\right)\end{array}$ & 0,36 & 0,22 & 0,19 & 5,38 & 1,96 & 0,79 & 5,77 & 3,15 & 0,85 \\
\hline $\begin{array}{l}\left.\Phi_{4} \text { (фракция } 300-470{ }^{\circ} \mathrm{C}\right) \\
\mathrm{F}_{4} \text { (fraction } 300-470^{\circ} \mathrm{C} \text { ) }\end{array}$ & 0,01 & 0,00 & 0,00 & 4,19 & 0,42 & 0,09 & 5,38 & 1,08 & 0,10 \\
\hline Азот/Nitrogen & 0,16 & 0,20 & 0,21 & 0,19 & 0,22 & 0,23 & 0,18 & 0,21 & 0,23 \\
\hline Углекислый газ/Carbon dioxide & 1,35 & 1,60 & 1,69 & 1,40 & 1,61 & 1,71 & 1,37 & 1,54 & 1,71 \\
\hline 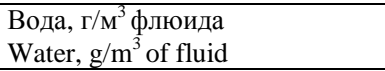 & 4,58 & 6,50 & 8,45 & 4,62 & 6,44 & 8,55 & 4,80 & 6,24 & 8,07 \\
\hline
\end{tabular}

Для протекания углекислотной коррозии необходимо наличие на поверхностях хвостовика и некоррозионно-стойкого внутрискважинного оборудования, контактирующих с восходящим потоком добываемого флюида, электролита за счет образования слоя или пленки водной жидкой фазы, насыщаемой диоксидом углерода. Поэтому важно определить: а) в какой фазе (паровой или жидкой) находится вода в потоке газоконденсатной смеси; б) в какой фазе (газовой или жидкой) находятся углеводороды; в) если имеет место образование водной и углеводородной жидких фаз, то в каком количественном соотношении они находятся, какого типа эмульсии они образуют «вода в масле» или «масло в воде»; г) какой режим восходящего многофазного потока обеспечивается в хвостовике, лифтовых трубах и на устье скважин при выполнении проектных технологических параметрах их эксплуатации.

Анализ результатов расчетов фазового поведения добываемого пластового флюида (газоконденсатной смеси с учетом влагосодержания) показал, что жидкая водная фаза из-за высокой температуры в пласте и скважинах не образуется ни в одной из исследуемых скважин в течение ближайшего 20-летнего периода их эксплуатации (рис. 2-4, табл. 4). Жидкая углеводородная фаза с незначительным содержанием растворенной в ней воды $(0,461 \ldots 0,754$ \% мольн.) появ- 
ляется на забое скважин № 1 и № 3 через 20 лет - к 2040 г., а в скважине № 2 уже через 10 лет - к 2030 г. При таких низких концентрациях в жидкой углеводородной фазе вода находится в молекулярнорастворенном состоянии и не образует с диоксидом углерода электролит. При этом избыточная масса воды находится в паровой фазе в составе газа.

Теперь важно выяснить, каковы гидродинамические условия течения восходящего потока газоконденсатной смеси в скважине при соблюдении проектного технологического режима эксплуатации: не происходит ли накопление жидкости на забое в хвостовике, в котором объемные скорости потока характе- ризуются наименьшими значениями в скважине из-за наибольшего давления и большим по сравнению с лифтовой колонной диаметром. При скоплении углеводородной жидкости на забое пусть с небольшим содержанием воды, растворенной в жидкой углеводородной фазе, со временем может образоваться сначала эмульсия типа «вода в масле», частичный объем которой при дальнейшем накоплении может подвергнуться инверсии со сменой на тип «масло в воде». В этом случае неизбежно образование электролита с протеканием углекислой коррозии незащищенного металла скважинного оборудования, в рассматриваемом здесь случае - хвостовика.

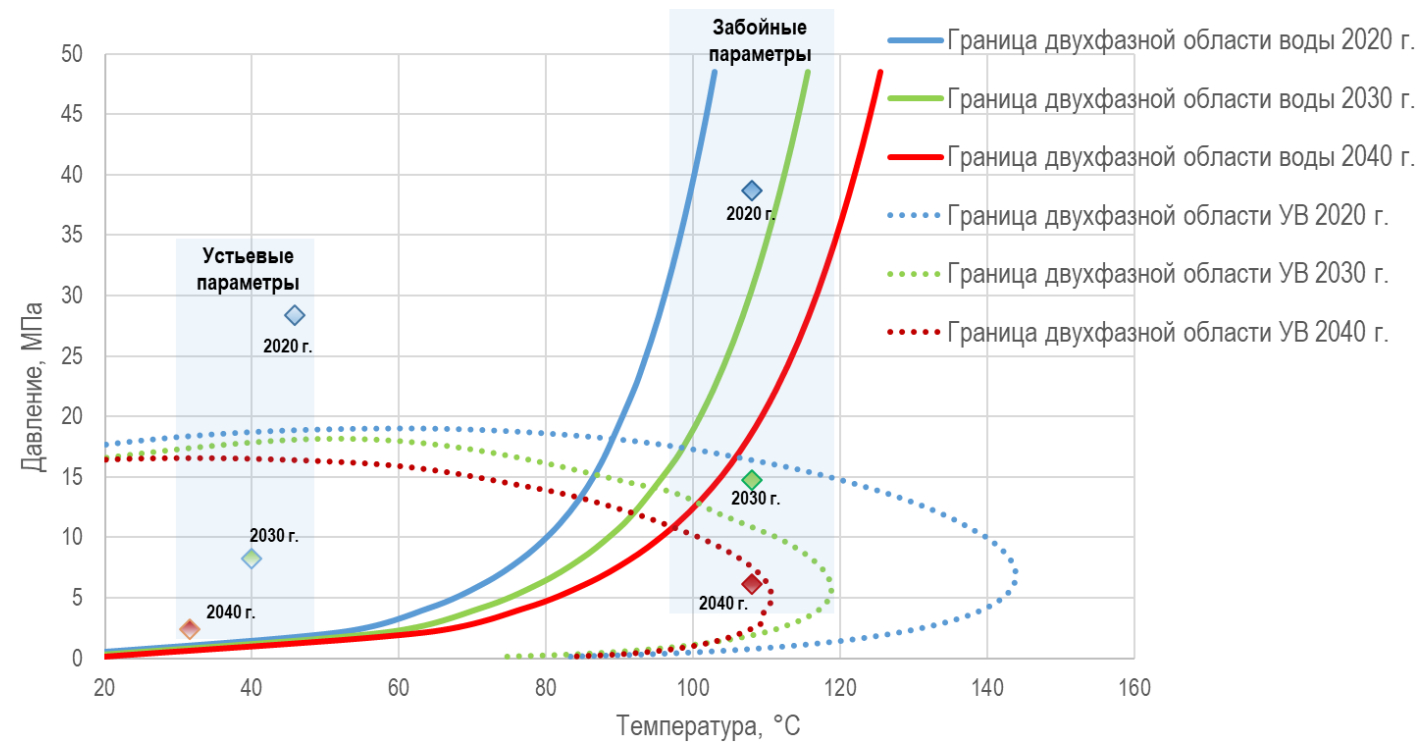

Pис. 2. Границы двухфазной области для воды и УВ и термобарические условия на забое и устье скважины № 1 по состоянию на 2020, 2030 и 2040 z2.

Fig. 2. Boundaries of the two-phase region for water and hydrocarbons $(H C)$ and thermobaric conditions at the bottomhole and wellhead of well no. 1 as of 2020, 2030 and 2040

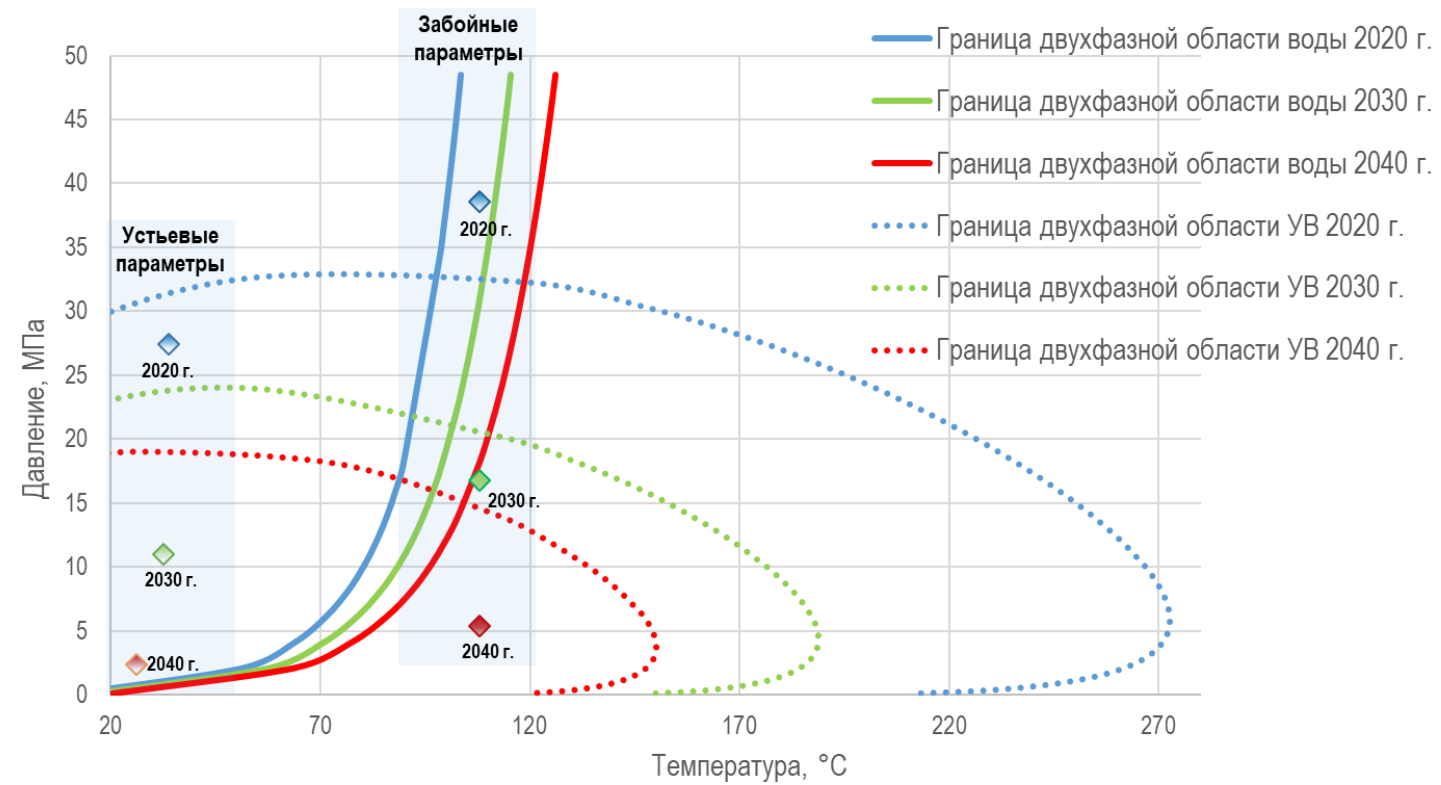

Pис. 3. Границы двухфазной области для воды и УВ и термобарические условия на забое и устье скважины № 2 по состоянию на 2020, 2030 и 2040 г2.

Fig. 3. Boundaries of the two-phase region for water and HC and thermobaric conditions at the bottomhole and wellhead of well no. 2 as of 2020, 2030 and 2040 


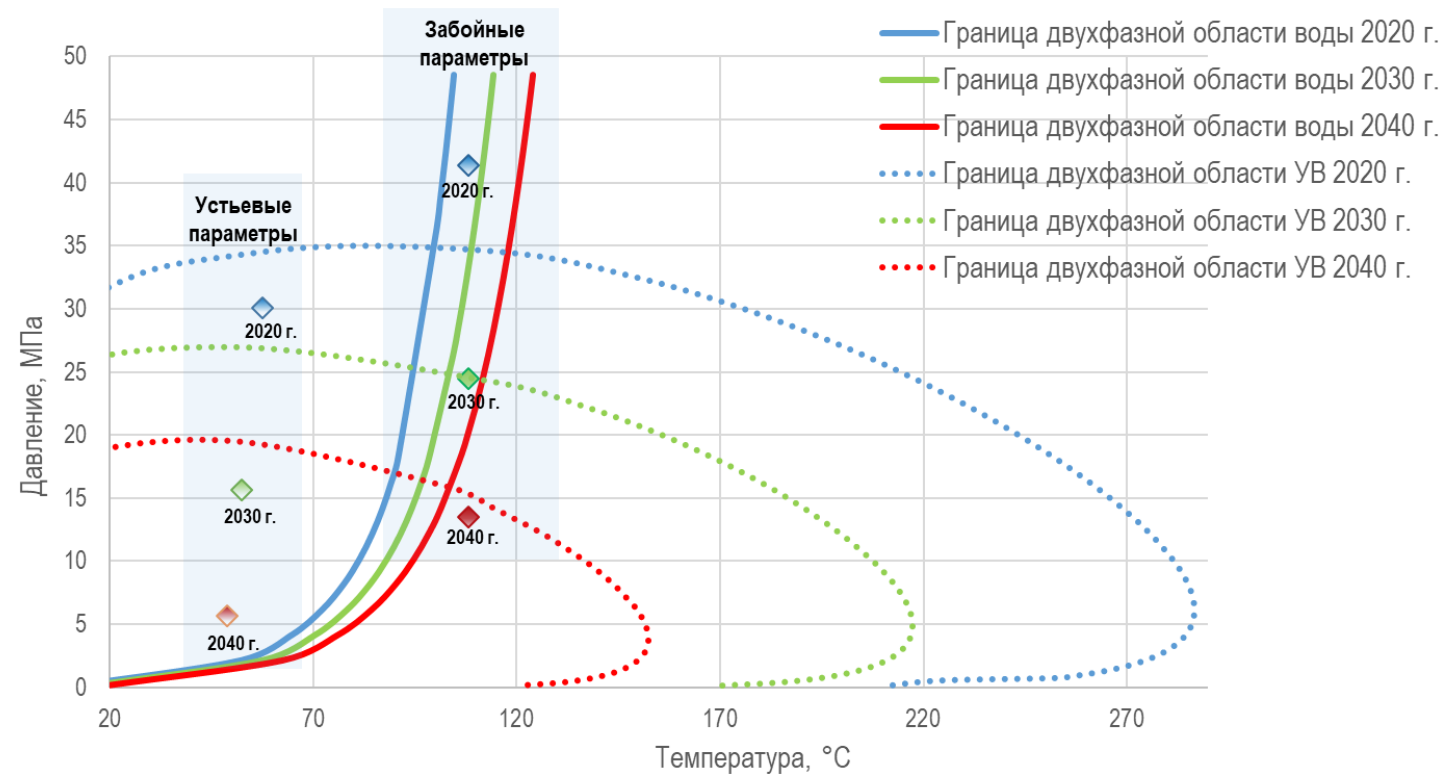

Pис. 4. Границы двухфазной области для воды и УВ и термобарические условия на забое и устье скважины № 3 по состоянию на 2020, 2030 и 2040 z2.

Fig. 4. Boundaries of the two-phase area for water and HC and thermobaric conditions at the bottomhole and wellhead of well № 3 as of 2020, 2030 and 2040

Таблица 4. Расчетные физико-химические свойства скважиной продукиии (2020, 2030, 2040 г2.)

Table 4. Estimated physical and chemical properties of the well production (in 2020, 2030, 2040)

\begin{tabular}{|c|c|c|c|c|c|c|c|c|c|}
\hline \multirow{3}{*}{$\begin{array}{l}\text { Физические свойства } \\
\text { Physical properties }\end{array}$} & \multicolumn{9}{|c|}{ Скважина/Well } \\
\hline & \multicolumn{4}{|c|}{1} & \multicolumn{3}{|c|}{2} & \multicolumn{2}{|r|}{3} \\
\hline & 2020 & 2030 & 2040 & 2020 & 2030 & 2040 & 2020 & 2030 & 2040 \\
\hline $\begin{array}{l}\text { Наличие жидкой углеводородной фазы на забое } \\
\text { скважины } \\
\text { Presence of liquid hydrocarbon phase } \\
\text { at the bottomhole }\end{array}$ & $\begin{array}{c}\text { нет } \\
\text { no }\end{array}$ & $\begin{array}{c}\text { нет } \\
\text { no }\end{array}$ & $\begin{array}{c}\text { да } \\
\text { yes }\end{array}$ & $\begin{array}{c}\text { нет } \\
\text { no }\end{array}$ & $\begin{array}{l}\text { да } \\
\text { yes }\end{array}$ & $\begin{array}{l}\text { да } \\
\text { yes }\end{array}$ & $\begin{array}{c}\text { нет } \\
\text { no }\end{array}$ & $\begin{array}{c}\text { нет } \\
\text { no }\end{array}$ & $\begin{array}{l}\text { да } \\
\text { yes }\end{array}$ \\
\hline $\begin{array}{l}\text { Наличие жидкой водной фазы на забое } \\
\text { скважины } \\
\text { Presence of liquid aqueous phase at the bottomhole }\end{array}$ & $\begin{array}{c}\text { нет } \\
\text { no }\end{array}$ & $\begin{array}{c}\text { нет } \\
\text { no }\end{array}$ & $\begin{array}{c}\text { нет } \\
\text { no }\end{array}$ & $\begin{array}{c}\text { нет } \\
\text { no }\end{array}$ & $\begin{array}{c}\text { нет } \\
\text { no }\end{array}$ & $\begin{array}{c}\text { нет } \\
\text { no }\end{array}$ & $\begin{array}{c}\text { нет } \\
\text { no }\end{array}$ & $\begin{array}{c}\text { нет } \\
\text { no }\end{array}$ & $\begin{array}{c}\text { нет } \\
\text { no }\end{array}$ \\
\hline $\begin{array}{l}\text { Плотность смеси, кг/ } \mathrm{M}^{3} \\
\text { Mixture density, } \mathrm{kg} / \mathrm{m}^{3}\end{array}$ & 340,25 & 142,65 & 51,74 & 325,23 & 155,30 & 57,74 & 345,20 & 228,87 & 112,59 \\
\hline $\begin{array}{l}\text { Плотность газовой фазы, кг/м³ } \\
\text { Gas phase density, } \mathrm{kg} / \mathrm{m}^{3}\end{array}$ & 340,25 & 142,65 & 51,30 & 325,23 & 151,44 & 55,95 & 345,20 & 228,87 & 111,43 \\
\hline $\begin{array}{l}\text { Плотность жидкой фазы, кг/м³ } \\
\text { Liquid phase density, } \mathrm{kg} / \mathrm{m}^{3}\end{array}$ & - & - & 612,35 & - & 557,74 & 630,89 & - & - & 583,14 \\
\hline $\begin{array}{l}\text { Молекулярная масса смеси, г/моль } \\
\text { Mixture molecular weight, g/mol }\end{array}$ & 27,44 & 24,12 & 23,05 & 26,59 & 23,50 & 22,40 & 27,18 & 24,44 & 22,46 \\
\hline $\begin{array}{l}\text { Молекулярная масса газовой фазы, г/моль } \\
\text { Gas phase molecular weight, g/mol }\end{array}$ & 27,44 & 24,12 & 22,89 & 26,59 & 22,96 & 21,82 & 27,18 & 24,44 & 22,26 \\
\hline $\begin{array}{l}\text { Молекулярная масса жидкой фазы, г/моль } \\
\text { Liquid phase molecular weight, g/mol }\end{array}$ & - & - & 86,35 & - & 71,20 & 92,11 & - & - & 77,57 \\
\hline $\begin{array}{l}\text { Мольная доля растворенной воды во всем } \\
\text { объеме жидкости } \\
\text { Dissolved water mole fraction in the entire volume } \\
\text { of liquid }\end{array}$ & - & - & $4,63 \cdot 10^{-3}$ & - & $6,96 \cdot 10^{-3}$ & $4,61 \cdot 10^{-3}$ & - & - & $7,54 \cdot 10^{-3}$ \\
\hline
\end{tabular}

Для оценки режима течения газожидкостного потока из симулятора фазового поведения газоконденсатной смеси были выгружены значения вязкостей газа и конденсата, поверхностного натяжения на границе газ-конденсат, коэффициента сверхсжимаемости газа, плотностей газовой и жидкой фаз для термобарических условий на забое и устье каждой из трех скважин для составов и проектных технологических режимов на 2020, 2030 и 2040 гг. Режим течения определялся по результату сравнения значения безразмерной скорости смеси [24]:

$$
w_{*}=\frac{4\left(q_{l}+q_{g}^{w c}\right)}{\pi d^{2}}\left(\frac{\rho_{l}-\rho_{g}}{g \sigma}\right)^{0,25}\left(\frac{\rho_{g}}{\rho_{l}}\right)^{0,5}
$$

со значением скорости нижней границы существования кольцевого режима:

$$
w_{b}=\left(0,82-0,0017 \mu^{-0,6}\right) \cdot 10^{((5,3+115 \mu)(1-\beta))},
$$

где $q_{l}$ и $q_{g}{ }^{w c}-$ дебиты конденсата и газа, приведенные к скважинным термобарическим условиям, м 3 /сутки; $\rho_{l}$ и $\rho_{g}-$ плотности конденсата и газа в скважинных

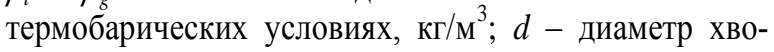
стовика или лифтовых труб, м; $\sigma$ - поверхностное 
натяжение на границе газ-конденсат, Н/м; $\mu=\frac{\mu_{g}}{\mu_{l}}-$ соотношение динамической вязкости газа и конденсата в скважинных термобарических условиях; $\beta=\frac{q_{g}^{w c}}{q_{g}^{w c}+q_{l}}-$ расходное объемное газосодержание.
Результаты расчета скоростей $w_{*}$ и $w_{b}$ показали, что в хвостовике, а тем более в лифтовых трубах на забое каждой из скважин, газожидкостной поток в рассматриваемый период разработки (до 2040 г.) движется в дисперсно-кольцевом режиме с превышением скорости $w_{b}$ более чем на порядок (табл. 5).

Таблица 5. Значения расходного газосодержания, безразмерной скорости нижней гранищы существования кольцевого режима и безразмерной скорости потока газоконденсатной смеси в хвостовике (2020, 2030, 2040 гz.)

Table 5. Values of the flow rate gas content, dimensionless velocity of the lower boundary of the existence of the annular regime and dimensionless flow rate of the gas-condensate liquid in the tailpipe (in 2020, 2030, 2040)

\begin{tabular}{|c|c|c|c|c|c|c|c|c|c|}
\hline \multirow{3}{*}{$\begin{array}{c}\text { Год разработки } \\
\text { Development year }\end{array}$} & \multicolumn{9}{|c|}{ Скважина/Well } \\
\hline & \multicolumn{3}{|c|}{1} & \multicolumn{3}{|c|}{2} & \multicolumn{3}{|c|}{3} \\
\hline & $\beta$ & $w_{b}$ & $w_{*}$ & $\beta$ & $w_{b}$ & $w_{*}$ & $\beta$ & $w_{b}$ & $w_{*}$ \\
\hline 2020 & 1,0000 & - & - & 1,0000 & - & - & 1,0000 & - & - \\
\hline 2030 & 1,0000 & - & - & 0,9905 & 1,239 & 8,848 & 1,0000 & - & - \\
\hline 2040 & 0,9992 & 0,834 & 15,635 & 0,9970 & 0,890 & 9,235 & 0,9975 & 0,892 & 29,568 \\
\hline
\end{tabular}

Кроме того, для определения гидродинамических условий полного и непрерывного выноса жидкой фазы с забоя на поверхность размерные скорости потока газа в хвостовике и башмаке лифтовых труб

$$
W=\frac{4 q_{g}^{w c}}{\pi d^{2} \beta}
$$

сравнивались с критической скоростью газа опрокидывания жидкой пленки, или скоростью реверса, при которой газ с дисперсной фазой жидкости в ядре потока движется вверх, а масса жидкости в кольцевой пленке, условно говоря, зависает, вычисляемой по формуле А.А. Точигина [24]

$$
W_{\text {rev }}=3,3\left(\frac{g \sigma \rho_{l}^{2}}{\rho_{l}-\rho_{g}}\right)^{0,25} \rho_{g}^{-0,5} .
$$

Результаты расчетов показали, что для всех трех скважин в течение рассматриваемого периода разработки до 2040 г. выполняется неравенство

$$
W>W_{\text {rev }}
$$

т. е. проектные режимы эксплуатации скважин обеспечивают полный и непрерывный вынос жидкой фазы и из хвостовика, и из башмака лифтовой колонны (табл. 6), т. к. скорость взвешивания частиц жидкости, диспергированной в ядре потока, всегда меньше скорости реверса пленки жидкости при дисперснокольцевом режиме течения вертикального потока.

Поскольку нестабильный конденсат не обладает электропроводимостью, пленка на внутренней поверхности хвостовика и лифтовых труб не является электролитом, и при непрерывной эксплуатации скважин в период до 2040 г. углекислотная коррозия хвостовиков исключается. При остановках скважин возможно стекание конденсата на забой, однако и в этом случае из-за незначительного содержания водной фазы в газоконденсатной смеси может образоваться эмульсия типа «вода в масле», что также не приведет к протеканию процесса коррозии.

В рамках данного исследования также был проведен анализ влияния количества воды конденсационного происхождения в составе добываемого флюида на смещение границы перехода воды в двухфазное состояние. Моделирование фазового поведения газоконденсатной смеси осуществлялось для компонентно-фракционного состава, приведенного в табл. 1, для которого изменялось удельное содержание конденсационной воды. Результаты расчетов приведены на pис. 5, на котором также показаны термобарические параметры на забое и устье скважины № 1 в 2020 г.

Таблица 6. Сравнение скоростей потока газа в хвостовике со скоростью опрокидывания кольцевой пленки конденсата при двухфазном течении газоконденсатной смеси

Table 6. Comparison of the gas flow rates in the tailpipe with the overturning rate of the annular condensate film in the two-phase flow of the gascondensate fluid

\begin{tabular}{|c|c|c|c|c|c|c|}
\hline \multirow{2}{*}{$\begin{array}{c}\text { Год разработки } \\
\text { Development } \\
\text { year }\end{array}$} & \multicolumn{6}{|c|}{ Скважина/Well } \\
\cline { 2 - 8 } & $W_{\text {rev }}$ & $W$ & $W_{\text {rev }}$ & $W$ & $W_{\text {rev }}$ & $W$ \\
\hline 2020 & - & - & - & - & - & - \\
\hline 2030 & - & - & 0,72 & 1,17 & - & - \\
\hline 2040 & 1,32 & 3,75 & 1,29 & 2,17 & 0,86 & 4,66 \\
\hline
\end{tabular}

Из рис. 5 следует, что увеличение удельного содержания воды смещает границу ее фазового состояния в сторону более высоких температур. При удельном содержании воды свыше 5,7 г/ $\mathrm{M}^{3}$ уже в 2020 г. не исключается появление жидкой водной фазы с образованием эмульсий типа «вода в масле» и возникновение рисков углекислотной коррозии хвостовика изза возможной инверсии эмульсии при дальнейшем росте содержания воды в продукции и проявлении ее электрической проводимости.

Поэтому мониторинг добычи воды раздельно по рассматриваемым скважинам составляет обязательную часть программы исследовательских работ, а в случае отклонения от проектных значений с резким ростом дебита воды потребуется техническая диагностика состояния хвостовика и проведение повторного моделирования фазового поведения газоконденсатной смеси с учетом актуализированных показателей. 


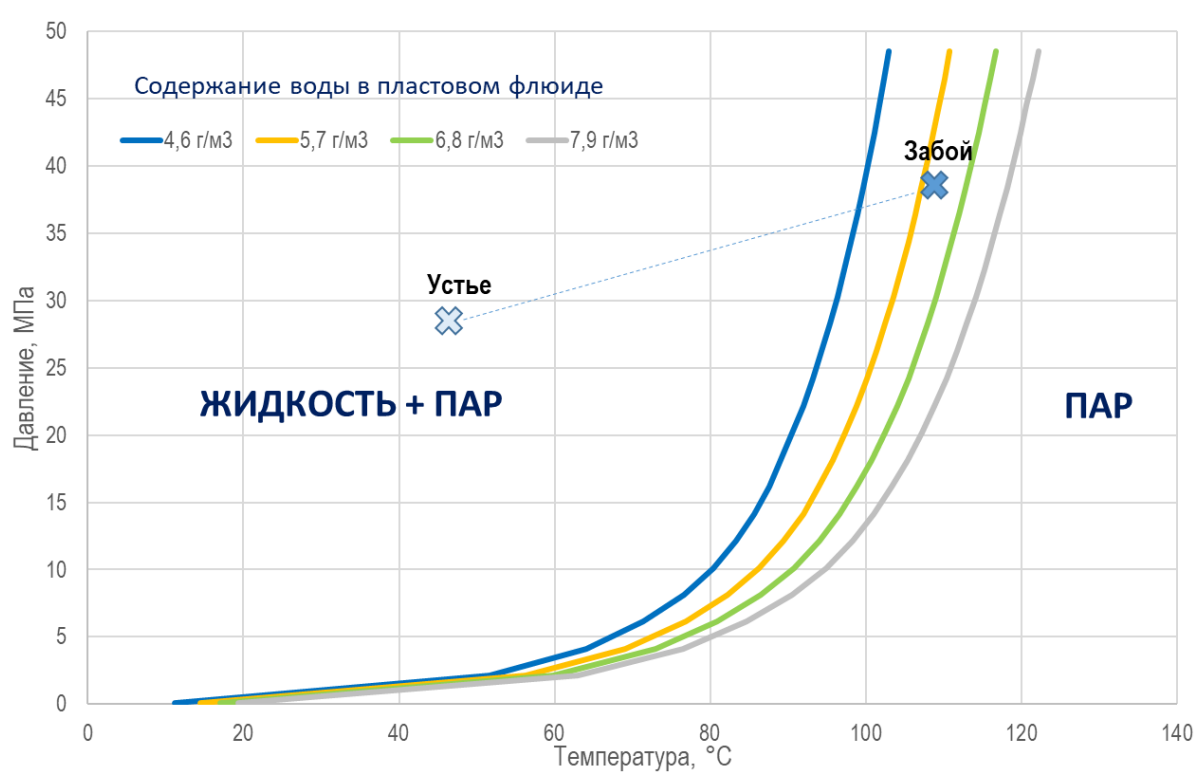

Pис. 5. Смещение грании двухфазной области воды, содержащейся в газоконденсатной смеси скважины № 1 с компонентно-фракиионном составом (табл. 1), при разных удельных содержаниях воды

Fig. 5. Displacement of the two-phase water region boundaries contained in the gas-condensate fluid of well no. 1 with a component-fractional composition (table 1), at different specific water contents

\section{Заключение}

Для определения предельных значений термобарических параметров технологических режимов эксплуатации высокотемпературных ачимовских газоконденсатных скважин с содержанием в добываемой продукции диоксида углерода, обеспечивающих физико-химические условия отсутствия электрохимической коррозии забойного оборудования хвостовиков из углеродистой стали на длительную перспективу, предложен комплексный методический подход, включающий моделирование фазового поведения влажной газоконденсатной смеси на забое и устье скважин и гидродинамический расчет многофазного потока в скважине.

На основе предлагаемого подхода изучено влияние изменения термобарических условий эксплуатации трех опытных скважинах на проектных технологических режимах в процессе разработки газоконденсатной залежи на фазовое поведение пластового флюида в интервале установки незащищенных от углекислотной коррозии хвостовиков с учетом влагосодержания добываемой продукции. Расчеты показали, что в двух из трех скважин из-за некоторого различия исходных составов газа и технологических режимов жидкая углеводородная фаза - нестабильный конденсат начинает выделяться только к двадцатому году эксплуатации, а по одной - к десятому году; при этом формирования жидкой водной фазы в забойных условиях не наблюдается ни по одной из скважин в течение всего прогнозного периода.

Учитывая, что вода не образует химических соединений с углеводородами, и при низкой концентрации в нестабильном конденсате (порядка 0,6\% мольн.) она находится в молекулярно-растворенном состоянии, сконденсированная жидкость не обладает электрической проводимостью. С другой стороны, продуктивные характеристики рассматриваемых трех скважин при проектных технологических режимах и диаметрах хвостовиков и лифтовых колонн обеспечивают в течение всего прогнозного периода значения скорости восходящего потока пластового флюида, превосходящие критические для полного и непрерывного выноса жидкости (в случае ее образования) на поверхность, т. е. накопления ее на забое не происходит. Физикохимические свойства пластового флюида при высокой температуре пласта и гидродинамические условия на забое и устье каждой из скважин позволяют прийти к заключению о невозможности протекания электрохимической коррозии хвостовиков в течение 20-летнего периода во всех трех скважинах.

Однако в случае значительного превышения удельного содержания конденсационной или иной воды в продукции скважин необходимо предусмотреть проведение мероприятий по технической диагностики состояния хвостовиков и повторное моделирование с учетом отклонений от проектных технологических режимов эксплуатации скважин. Поэтому освоение скважин с хвостовиками из углеродистой стали после операции ГРП необходимо проводить в сжатые сроки, а в процессе ГРП использовать водные растворы с добавкой ингибиторов коррозии либо иные реагенты, не обладающие коррозионной агрессивностью.

Таким образом, предлагаемый подход позволяет:

- обосновывать антикоррозионные режимы на стадии проектирования скважин, когда в проектных решениях возможна замена части подземного оборудования из дорогих коррозионностойких сталей на более дешевые углеродистые стали без снижения уровня надежности и безопасности;

- прогнозировать возможность протекания процессов углекислотной коррозии не только подземного оборудования, но и трубопроводов обвязки скважин и системы сбора газа, выполненных из углеродистой стали. 


\section{СПИСОК ЛИТЕРАТУРЫ}

1. Маркин А.Н., Низамов Р.Э. СО2-коррозия нефтепромыслового оборудования. - М.: ОАО «ВНИИОЭНГ», 2003. - 187 с.

2. Кузнецов В.П. Основные факторы углекислотной коррозии газоконденсатных скважин и их изменение в процессе эксплуатации месторождений: дис. ... канд. техн. наук. - Краснодар, 1974. - $143 \mathrm{c}$

3. Легезин Н.Е. Противокоррозионная защита систем добычи, сбора и транспорта природного газа с применением ингибиторов: дис. ... д-ра техн. наук. - М, 1988. - 284 с.

4. Освоение участков ачимовских отложений ООО «Газпром добыча Уренгой» / А.Ю. Корякин, И.В. Игнатов, А.Ю. Неудахин, М.Г. Жариков, С.А. Скрылев, А.Н. Нестеренко, В.П. Тюрин // Научный журнал российского газового общества. - 2017. № 3. - С. 21-28.

5. Курчиков А.Р., Бородкин В.Н., Хромцова А.В. Условия формирования и атлас текстур пород ачимовского комплекса севера Западной Сибири. - Новосибирск: Изд-во СО РАН, Зап.Сиб. фил. ин-та нефтегазовой геологии и геофизики им. А.А. Трофимука СО РАН, 2010. - 130 с.

6. Корякин А.Ю., Кобычев В.Ф. Перспективные направления развития Уренгойского комплекса // Сборник научных трудов ООО «Газпром добыча Уренгой». - М.: ООО «ИД Недра», 2018. - C. 350-355.

7. Yusupov A. Mathematical simulation of the rate of carbon dioxide corrosion at the facilities of Gazpromdobycha Urengoy LLC // E3S Web of Conferences. - 2019. - V. 121. - P. 1-5.

8. Koriakin A. Carbon dioxide corrosion at the objects of the second district of Achimovsk deposits of Urengoy oil and gas bearing complex // International Journal of Mechanical Engineering and Technology. - 2018. - V. 9. - P. 1073-1080.

9. Опыт подбора ингибиторов коррозии для защиты от углекислотной коррозии объектов второго участка ачимовских отложений Уренгойского нефтегазоконденсатного месторождения / А.Ю. Корякин, Д.В. Дикамов, И.В. Колинченко, А.Д. Юсупов, Д.Н. Запевалов, Р.К Вагапов // Оборудование и технологии для нефтегазового комплекса. - 2018. - № 6. - С. 48-55.

10. Совершенствование конструкций скважин на ачимовские залежи Уренгойского нефтегазоконденсатного месторождения / А.Ю. Корякин, М.Г. Жариков, И.А. Яскин, С.А. Скрылев, Р.П. Гресько // Газовая промышленность. - 2017. - № 9. С. 76-79.

11. Скорчеллетти В.В. Теоретическая электрохимия. - Л.: Госхимиздат, 1963. - 609 c.

12. Modeling binary mixtures of water + light hydrocarbon using the perturbed-chain statistical associating fluid theory with induced association: improvement in describing all equilibrium phases /
P.T. Sugata, S.K. Jeffrey, D.V. Steven, M.L. Rosaly // ACS Earth and Space Chemistry. - 2019. - V. 3. - Iss. 11. - P. 2569-2581.

13. Soave G. Equilibrium constants from a modified Redlich-Kwong equation of state // Chemical Engineering Science. - 1972. V. 27. - P. 1197-1203.

14. Li C., Jia W., Wu X. Application of Lee-Kesler equation of state to calculating compressibility factors of high pressure condensate gas // Energy Procedia. - 2012. - V. 14. - P. 115-120.

15. Peng D.Y., Robinson D.B. A new two-constant equation of state // Industrial \& Engineering Chemistry Fundamentals. - 1976. V. 15. - P. 59-64

16. Robinson D.B., Peng D.Y., Chung S.Y. The development of the Peng-Robinson equation and its application to phase equilibrium in a system containing methanol // Fluid Phase Equilibria. 1985. - V. 24. - Р. 25-41.

17. Модификация кубических уравнений Пенга-Робинсона и Брусиловского для описания поведения воды и метанола / Ю.В. Калиновский, А.В. Минеев, А.И. Пономарев // Нефтегазовое дело. - 2006. - Т. 4. - № 1. - С. 293-297.

18. Пономарев А.И., Калиновский Ю.В. Комплексирование газоконденсатных и гидродинамических исследований скважин для определения характеристик многофазного потока // Наука и техника в газовой промышленности. - 2017. - № 2 (70). C. 7-16.

19. High pressure phase behavior modeling of asymmetric alkane + alkane binary systems with the RKPR EOS / M.D. Cismondi, M.V. Galdo, M.J. Gomez, N.G. Tassin, M. Yanes // Fluid Phase Equilibria. - 2014. - V. 362. - P. 125-135.

20. Калашников О.В. Моделирование фазового поведения углеводородов: выбор уравнения состояния // Экотехнологии и ресурсосбережение. - 2003. - № 1.- С. 22-30.

21. Lopez-Echeverry J., Reif-Acherman S., Araujo-Lopez E. PengRobinson equation of state: 40 years through cubics // Fluid Phase Equilibria. - 2017. - V. 447. - P. 39-71.

22. Peng D.Y., Robinson D.B., Bishnoi P.R. The use of the SoaveRedlich-Kwong equation of state for predicting condensate fluid behavior // 9th World Petroleum Congress. - Tokyo, 1975. P. 1-12.

23. Literature review on modeling and simulation of energy infrastructures from a resilience perspective / J. Wanga, W. Zuo, L. Barbarigos, X. Lu, J. Wang, Y. Lind // Reliability Engineering \& System Safety. - 2019. - V. 183. - P. 360-373.

24. Движение газожидкостных смесей в трубах / В.А. Мамаев, Г.Э. Одишария, О.В. Клапчук, А.А. Точивин, Н.И. Семенов. М.: Недра, 1978. - 270 с.

Поступила: 29.07.2020 г.

\section{Информация об авторах}

Пономарев А.И., доктор технических наук, профессор, заведующий кафедрой разработки и эксплуатации газовых и нефтегазоконденсатных месторождений Уфимского государственного нефтяного технического университета.

Иванов Н.В., аспирант кафедры машин и оборудования нефтяной и газовой промышленности Российского государственного университета нефти и газа (НИУ) им. И.М. Губкина.

Юсупов А.Д., аспирант кафедры разработки и эксплуатации газовых и нефтегазоконденсатных месторождений Уфимского государственного нефтяного технического университета. 
UDC $622.279,620.193$

\title{
NEW METHODICAL APPROACH TO THE $\mathrm{CO}_{2}$-CORROSION ESTIMATION OF HIGH-TEMPERATURE GAS-CONDENSATE WELLS EQUIPMENT
}

\author{
Alexander I. Ponomarev'1, \\ pnmrv@mail.ru \\ Nikolay V. Ivanov², \\ inv1412@yandex.ru \\ Alexander D. Yusupov¹,
aleksandr_yusupov@list.ru
1 Ufa State Petroleum Technological University,
1, Kosmonavtov street, Ufa, 450062, Russia.
2 Gubkin Russian State University of Oil and Gas,
65, Leninsky avenue, Moscow, 119991, Russia.
}

The relevance. The prospects for increasing gas condensate - valuable raw material for oil refining and petrochemicals, are largely associated with the further development of the achimov gas condensate deposits in the north of Western Siberia. Large depths, abnormally high reservoir pressure and high temperature of low-productivity formations, along with the presence of carbon dioxide in the gascondensate formation fluid, put forward, first of all, increased demands on the quality of well completion and hydraulic fracturing operations, the reliability of structures and materials of underground well equipment. These factors are responsible for the high cost of project implementation and operational risks of gas and condensate production, and therefore justification of safe operating conditions for achimov is an urgent scientific and technical task.

The main aim of the research is the limiting thermobaric parameters determination of the technological operating modes of the achimov gas condensate wells, taking into account the production of $\mathrm{CO}_{2}$ in products.

Objects: reservoir gas-condensate fluid and bottomhole equipment of three achimov gas-condensate wells with carbon steel tailpipes, unstable to $\mathrm{CO}_{2}$-corrosion.

Methods: modeling the phase behavior of the produced reservoir fluid in bottomhole conditions by the GasCondNeft software.

Results. Phase behavior thermodynamic calculations of the reservoir fluid, taking into account its moisture content, showed that a reservoir pressure decrease at the location of the three considered wells during the development of the achimov deposits for 20 years under project operation modes leads to the formation of a two-phase fluid (gas-unstable condensate) in bottomhole thermobaric conditions. Moreover, the aqueous liquid phase due to the high temperature of the flow at the well bottomhole is not formed during the entire calculation period. Hydrodynamic parameters calculations of the gas-liquid upward flow showed that high flow rates of well products provide conditions for the complete and continuous removal of unstable condensate by the gas flow from the bottom to the surface of all considered wells for the entire 20-year period, thereby preventing the physical and chemical conditions of electrolyte formation on tailpipes surface and carbon dioxide corrosion.

\section{Key words:}

Gas condensate fluid, carbon dioxide, tailpipe, well operation parameters, simulator, phase diagrams, water and hydrocarbon dew point lines, multiphase flow regime, carbon dioxide corrosion, anticorrosive well operation.

\section{REFERENCES}

1. Markin A.N., Nizamov R.E. $\mathrm{CO}_{2}$-korroziya neftepromyslovogo oborudovaniya $\left[\mathrm{CO}_{2}\right.$-corrosion of oilfield equipment]. Moscow, VNIIOENG Publ., 2003. 187 p.

2. Kuznetsov V.P. Osnovnye factory uglekislotnoy korrozii gazokondensatnykh skvazhin i ilh izmenenie $v$ protsesse ekspluatatsii mestorozhdeniy Dis. Kand. nauk [Main factors of carbon dioxide corrosion of gas condensate wells and their changes during field operation. Cand. Diss.]. Krasnodar, 1974. 143 p.

3. Legezin N.E. Protivokorrozionnaya zashchita system dobychi, sbora i transporta prirodnogo gaza s primeneniem ingibitorov. Dis. Dokt. nauk [Corrosion protection of natural gas production, gathering and transportation systems using inhibitors. Dr. Diss.] Moscow, 1988. 284 p.

4. Koryakin A.Yu., Ignatov I.V., Neudakhin A.Yu., Zharikov M.G., Skrylev S.A., Nesterenko A.N., Tyurin V.P. Development of blocks of achimov deposits Gazprom dobycha Urengoy LLC. Nauchny zhurnal rossiyskogo gazovogo obshchestva, 2017, no. 3, pp. 21-28. In Rus.

5. Kurchikov A.R., Borodkin V.N., Khromctsova A.V. Usloviya formirovaniya i atlas tekstur porod achimovskogo kompleksa severa Zapadnoy Sibiri [Formation conditions and atlas of rocks of the Achimov complex textures in the north of Western Siberia]. Novosibirsk, SO RAN Publ., 2010. 130 p.

6. Koryakin A.Yu., Kobychev V.F. Perspektivnye napravleniya razvitiya Urengoyskogo kompleksa [Prospective directions of development of the Urengoy oil and gas complex]. Sbornik nauchnylh trudov $0 O O$ «Gazprom dobycha Urengoy» [Collection of research papers of Gazprom dobycha Urengoy LLC]. Moscow, Nedra Publ., 2018. pp. 350-355.

7. Yusupov A. Mathematical simulation of the rate of carbon dioxide corrosion at the facilities of Gazprom dobycha Urengoy LLC. E3S Web of Conferences, 2019, vol. 121, pp. 1-5.

8. Koriakin A. Carbon dioxide corrosion at the objects of the second district of Achimovsk deposits of Urengoy oil and gas bearing complex. International Journal of Mechanical Engineering and Technology, 2018, vol. 9, pp. 1073-1080.

9. Koryakin A.Yu., Dikamov D.V., Kolinchenko I.V., Yusupov A.D., Zapevalov D.N., Vagapov R.K Experience of corrosion inhibitors selection to protect the objects of the second site of achimovsky deposits of Urengoy oil and gas-condensate field from carbon acid corrosion. Equipment and technologies for oil and gas complex, 2018, no 6,pp. 48-55. In Rus.

10. Koryakin A.Yu., Zharikov M.G., Yaskin I.A., Skrylev S.A., Gresko R.P. Improving the well design of the Achimovsk deposit of the 
Urengoy oil and gas condensate field. Gas Industry, 2017, no. 9, pp. 76-79. In Rus.

11. Skorchelletti V.V. Teoreticheskaya elektrokhimiya [Theoretical electrochemistry]. Leningrad, Goskhimizdat Publ., 1963. 609 p.

12. Sugata P.T., Jeffrey S.K., Steven D.V., Rosaly M.L. Modeling binary mixtures of water + light hydrocarbon using the perturbedchain statistical associating fluid theory with induced association improvement in describing all equilibrium phases. ACS Earth and Space Chemistry, 2019, vol. 3, pp. 2569-2581.

13. Soave G. Equilibrium constants from a modified Redlich-Kwong equation of state. Chemical Engineering Science, 1972, vol. 9, pp. 1197-1203.

14. Li C., Jia W., Wu X. Application of Lee-Kesler equation of state to calculating compressibility factors of high-pressure condensate gas. Energy Procedia, 2012, vol. 14, pp. 115-120.

15. Peng D.Y., Robinson D.B. A new two-constant equation of state. Industrial \& Engineering Chemistry Fundamentals, 1976, vol. 15 pp. 59-64.

16. Robinson D.B., Peng D.Y., Chung S.Y. The development of the Peng-Robinson equation and its application to phase equilibrium in a system containing methanol. Fluid Phase Equilibria, 1985, vol. 24, pp. 25-41.

17. Kalinovskiy Yu.V., Mineev A.V., Ponomarev A.I. Modification of the Peng-Robinson and Brusilovsky cubic equations to describe the behavior of water and methanol. Oil and gas business, 2006 , vol. 1, pp. 293-297. In Rus.
18. Ponomarev A.I., Kalinovskiy Yu.V. Integration of gas condensate and hydrodynamic studies of wells to determine the characteristics of multiphase flow. Science and Technology in the Gas Industry, 2017, no. 2, pp. 7-16. In Rus.

19. Cismondi M.D., Galdo M.V., Gomez M.J., Tassin N.G., Yanes M. High pressure phase behavior modeling of asymmetric alkane + alkane binary systems with the RKPR EOS. Fluid Phase Equilibria, 2014, vol. 362, pp. 125-135.

20. Kalashnikov O.V. Modeling the phase behavior of hydrocarbons: the choice of the equation of state. Ecotechnology and resource saving, 2003, vol. 1, pp. 22-30. In Rus.

21. Lopez-Echeverry J., Reif-Acherman S., Araujo-Lopez E. PengRobinson equation of state: 40 years through cubics. Fluid Phase Equilibria, 2017, vol. 447, pp. 39-71.

22. Peng D.Y., Robinson D.B., Bishnoi P.R. The use of the SoaveRedlich-Kwong equation of state for predicting condensate fluid behavior. IX World Petroleum Congress. Tokyo, 1975. pp. 1-12.

23. Wanga J., Zuo W., Barbarigos L., Lu X., Wang J., Lind Y. Literature review on modeling and simulation of energy infrastructures from a resilience perspective. Reliability Engineering \& System Safety, 2019, vol. 183, pp. 360-373.

24. Mamaev V.A., Odishariya G.E., Klapchuk O.V., Tochivin A.A., Semenov N.I. Dvizhenie gazozhidkostnylh smesey v trubakh [The movement of gas-liquid mixtures in pipes]. Moscow, Nedra Publ., 1978. $270 \mathrm{p}$.

\section{Information about the authors}

Alexandr I. Ponomarev, Dr. Sc., professor, Ufa State Petroleum Technological University. Nikolay V. Ivanov, postgraduate student, Gubkin Russian State University of Oil and Gas. Alexandr D. Yusupov, postgraduate student, Ufa State Petroleum Technological University. 